\title{
REVIEW
}

\section{Access block and emergency department overcrowding}

\author{
Roberto Forero'*, Sally McCarthy², Ken Hillman' \\ This article is one of eleven reviews selected from the Annual Update in Intensive Care and Emergency Medicine 2011 (Springer Verlag) and \\ co-published as a series in Critical Care. Other articles in the series can be found online at http://ccforum.com/series/annual. Further \\ information about the Annual Update in Intensive Care and Emergency Medicine is available from http://www.springer.com/series/8901
}

\section{Introduction}

Access block affecting the emergency department (ED), also known as boarding in the United States and Canada, can be described as a phenomenon comprising almost all the challenges in the world of modern EDs. We use the analogy of parallel universes to illustrate both the complexity and the severity of the problem. In the world of physics, many attempts have been made to create a mathematical solution that can answer the more basic questions about physical phenomena in the universe. This has been known as 'Theory of Everything'. Albert Einstein spent 30 years of his life trying to solve this 'Theory of Everything', but failed [1].

In the parallel universe of emergency medicine, access block, or delays in admission of patients to hospital inpatient areas from EDs, can be described as a whole system problem, the equivalent to the 'Theory of Everything. It remains a fundamental challenge, prompting comments such as: "Access Block and ED overcrowding have created a dynamic tension and the future of emergency medicine will be determined by the resolution of this conflict" [2].

Despite access block and overcrowding in EDs being redefined, investigated and managed in multiple ways, it is far from being resolved $[3,4]$. This chapter summarizes the evidence from access block studies, exploring hospital, patient or medical interventions to reduce the impact of access block in terms of ambulance diversion, impaired access to emergency care, compromised clinical care, prolonged pain and suffering as well as increased comorbidity and mortality associated with prolonged ED length of stay.

\footnotetext{
*Correspondence: r.forero@unsw.edu.au

'The Simpson Center for Health Systems Research, Liverpool Hospital, Locked Bag 7103, Liverpool BC, NSW, 1871, Australia

Full list of author information is available at the end of the article
}

(c) 2011 Springer-Verlag Berlin Heidelberg.

This work is subject to copyright. All rights are reserved, whether the whole or part of the material is concerned, specifically the rights of translation, reprinting, reuse of illustrations, recitation, broadcasting, reproduction on microfilm or in any other way, and storage in data banks. Duplication of this publication or parts thereof is permitted only under the provisions of the German Copyright Law of September 9 , 1965 , in its current version, and permission for use must always be obtained from Springer-Verlag. Violations are liable for prosecution under the German Copyright Law.
According to the Australasian College for Emergency Medicine (ACEM) access block is defined as "the situation where patients are unable to gain access to appropriate hospital beds within a reasonable amount of time, no greater than 8 hours" and 'overcrowding' refers to "the situation where ED function is impeded by the number of patients waiting to be seen, undergoing assessment and treatment, or waiting for departure, exceeding the physical or staffing capacity of the department" $[5,6]$.

Access block has been linked to increased ED waiting time for medical care and leads to ED overcrowding. This overcrowding is generally accepted as a reason for decreased efficiency and quality of care, and has also been linked to an increased incidence of adverse events $[5,6]$. It has been indicated that the 'Theory of Everything' has some fundamental problems [1]. Access block is also full of them. The first problem is that most interventions produced to date have had some positive effects, although not necessarily on access block itself; however, they have been of short duration or have had limited or short term impact [7].

In the last decade, the UK reduced the acceptable waiting time for admission to hospital from the ED to four hours. This is known as the 'Four-Hour Target', where $98 \%$ of patients must be seen and treated within four hours. It has produced significant effects (both positive and negative). In Australia and New Zealand, the positive effect generated in the UK prompted the New Zealand government to implement a similar version - or a 'six-hour target'. In Australia, the State of Western Australia decided to implement the 'four hour target' and its implementation is in the final stages. The South Australian health system is also in the process of implementing it. In relation to the negative effect, in the UK it has been reported that the 'four hour target' has been overused in an inflexible way by some hospitals. A 
Mid-Staffordshire Trust report claimed that many patients died because of substandard care driven by the Trust management's wish to achieve Key Performance Indicators (KPIs) at any cost. This report has been tabled in the British parliament and the continuation of this policy has been re-considered by the new UK government $[8,9]$. However, the dilemma remains - is the four or six hour rule going to achieve its purpose?

The second problem is that access block has been described as a disease where the symptoms can be managed but the fundamental problem remains as yet unsolved [10].

The third problem is that access block is frequently associated with bed capacity and there are studies confirming that hospital wards cannot be run at around $100 \%$ occupancy for long without considerable risk to patients as a result of delayed admission from the ED $[11,12]$. Most hospitals are run at full capacity and the problem is exacerbated by significant pressures in health care, such as natural events (earthquakes, flu pandemics, floods, bushfires, etc.) or long waiting lists for elective surgery. It has been demonstrated that a finite-capacity system with variable demand cannot sustain both full utilization and full availability. A single level of ideal or safe occupancy suitable for all situations is a simplistic interpretation and application of the underlying science [12]. Therefore, specific studies and actions are necessary to understand and deal with the problems of long waiting lists and access block in any given health care facility [12].

\section{Magnitude of the problem}

Recent literature reviews have demonstrated that most authors agree on three things [7,13-15]:

A.the problem is getting worse

B. it is associated with poor health outcomes, and

C. there are mainly three levels or factors associated with the problem, namely patient centered, hospital/system and clinical factors

In relation to patient-centered factors, we are interested in understanding the operation of EDs and how this is impacted by access block and overcrowding, and the resulting effects on patients and staff. To do so we need to identify clinical/system factors, and which interactions may be influenced across departments, such as EDs, medical and surgical wards, intensive care units (ICUs), operating rooms, radiology departments and ambulance services.

It has been confirmed that in Australia, the ED rate of presentation per 1,000 population increased by $35 \%$ between 2003 and 2008. There were 1.98 million more presentations to Australian EDs in 2006-2007 (6.7 million) compared to the 2005-2006 financial year (4.8 million) [7]. As a result of the increased demand and co-incident bed shortages, occupancy rates in most hospitals were greater than 85\%, which has been considered the maximum level for efficiency [6,11-15].

\section{Hospital and system factors}

In order to understand the complexity of the problem, we need to understand the flow on effect of access block on EDs and the cascading effect on other services.

\section{Policy interventions}

Easy answers are elusive (Fig. 1). The literature has identified multiple policy interventions that have temporarily reduced the impact of access block and ED crowding. However, one of the challenges is to identify which interventions have been implemented and how they have affected specific areas, namely EDs, ambulance services, radiology, operating rooms, medical and/or surgical wards, and ICUs.

There is strong evidence suggesting that initiatives to avoid or reduce the duration of hospital admission such as transit lounges, observation wards, multidisciplinary team interventions, additional ED staff and rescheduling of some services have produced positive effects, while ED expansion on its own has not been demonstrated to have a significant effect on hospital diversion nor length of stay [16-21].

Many hospitals have reported that, by increasing staff capacity, they have been able to reduce ED length of stay [22]. In addition, other initiatives have combined multiple strategies to avoid admission such as transit lounges, short stay wards, and transit bays with alternatives to admission such as fast track and ambulance diversion [16,23-27]. Other initiatives have transcended from the ED to other services. For example, it has been found that interventions initiated by nurses, such as nurse initiated X-ray services improve patient satisfaction, without impact on access block or ED crowding. Mental health patients can benefit from the co-location of psychiatric emergency services within the ED, by the earlier delivery of specialist mental health care [28-30].

In a recent literature review, it was confirmed that at least $62 \%$ of interventions reporting strategies to manage existing resources, had at least one positive effect on different parts of the health system [7]. Hospital restructuring has also been found to have a positive effect in Canada [31]. However, not all interventions have had the same effect. Access to general practitioner services within the hospital has had mixed results. It has been considered unsuccessful in some hospitals in Australia and New Zealand but has been reported effective in diverting patients from EDs in the Netherlands [32-34]. No Australasian study has reported any effect on the availability of co-located services at reducing access block or ED crowding, but they have shown that very low acuity patients consume 


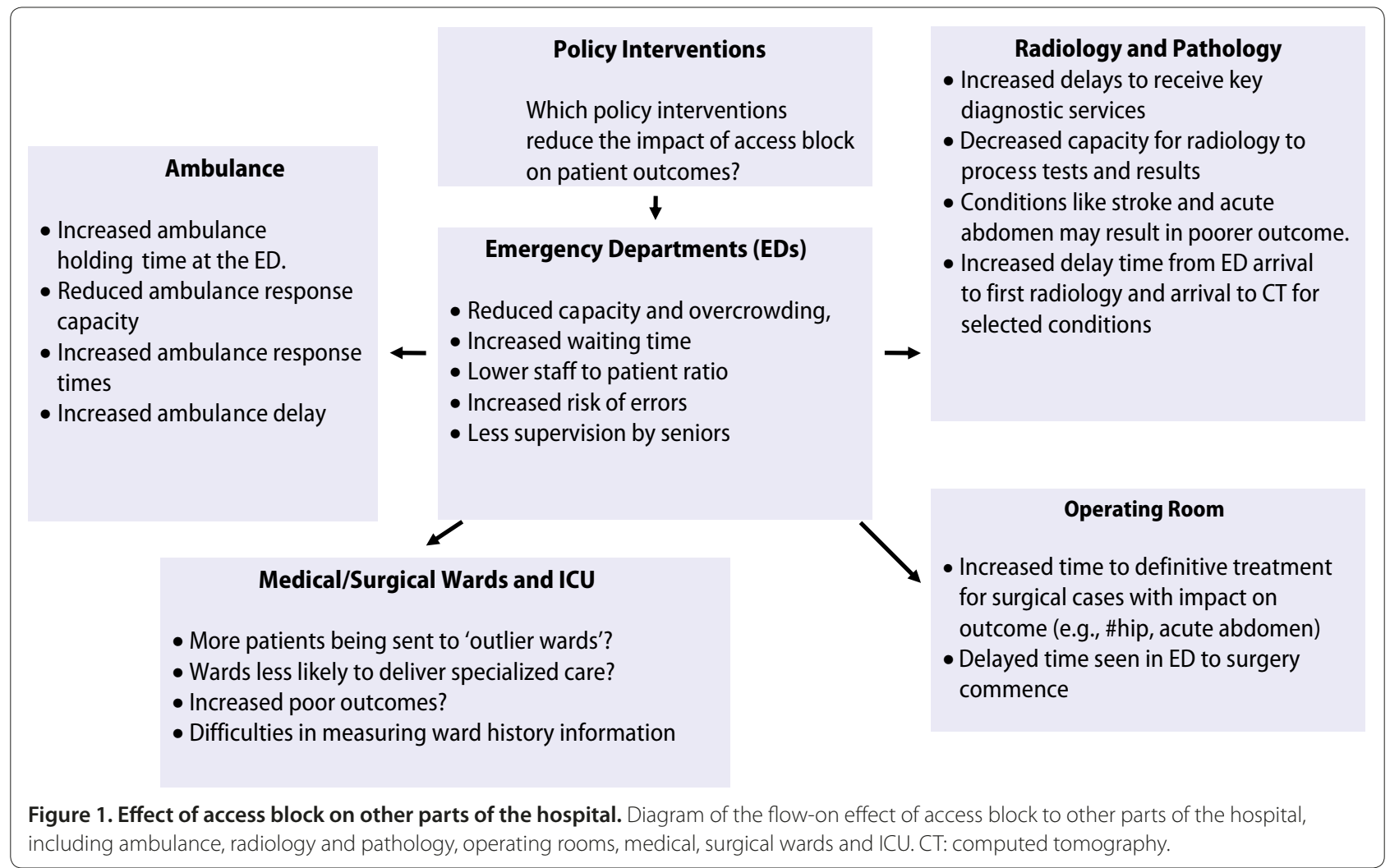

a minimal part of ED resources and are cheaply and quickly treated at hospital EDs [7].

Individual initiatives, such as expanding the ED capacity from 24 to 54 beds, in isolation, without addressing other bottlenecks in the hospital, are ineffective and insufficient to produce significant changes on ambulance diversion or the proportion of patients who left without being seen [21].

In general, policies to reduce or control overcrowding have been associated with the majority of access block cases in Canada. They are perceived by ED directors as largely ineffective [35]. In the UK, policies such as early hospital discharge and the four hour target have had unintended consequences, such as the creation of incomplete episodes of care that have resulted in increases in the percentage of readmissions $[8-9,13]$.

\section{Emergency departments}

Access block and consequent ED overcrowding constitute the greatest threat to quality emergency care. Inadequate hospital bed capacity and flexibility, or lack of an available bed when it is needed, result in the delay of transfer of patients from ED to an appropriate in-hospital bed, particularly to medical and surgical wards as well as ICUs [5-7].

Access block and the ED overcrowding it causes, constitute the greatest threat to quality emergency care, being associated with increased risk of errors, delayed time-critical care, increased morbidity and excess deaths [7,10,11,31,36-40].

There is evidence that ED length of stay targets such as the 'four hour target' can produce important changes in work practices, hospital and system processes, and discharge planning, leading to more efficient use of resources and reducing ED overcrowding [41]. However, evidence also demonstrates that emphasis on time alone, rather than quality of patient care, can adversely affect patient safety and staff morale $[8,9]$.

\section{Ambulance service}

Ambulance bypass or diversion is the situation where ambulances cannot deliver patients to the closest hospital as a result of overcrowding in that hospital. It has been identified especially in urban areas as one of the more serious issues resulting from access block [7]. Access block and overcrowding have also resulted in extended delays either at the scene in the community or in transport time from the scene to hospital. Simple expansion of the ED does not have a significant effect on ambulance diversion [21]; instead, ED length of stay increased [21]. In addition, the improvement in the proportion of patients who left the ED without being seen was minimal. Internet-accessible emergency department workload information may reduce ambulance diversion [27]. The 
main effects of access block on ambulance services include increased ambulance holding time at the ED, reduced ambulance response capacity, increased ambulance response times, increased ambulance delays, and increased mortality [38].

\section{Radiology and pathology}

Rapid access to diagnostic services from EDs is important [42]. It has been found that radiology and pathology tests initiated by nurses improve patient satisfaction $[28,29]$. There is evidence of increased test ordering using these providers [43]. It has also been documented that EDs and inpatient units are facing challenges associated with the impact of access block and ED overcrowding on radiology and pathology. Increased demand for imaging can result in delays to receiving those services as well as errors in the production and processing of radiology orders [6,7]. The same has been reported for pathology services, resulting in poor health outcomes for certain conditions such as stroke and acute abdominal conditions [43,44].

\section{Operating room}

Access block can cause delays to definite treatment for surgical cases with adverse impact on outcome, such as hip fractures and acute abdominal conditions. This is often exacerbated by operating room closures during holiday periods such as Christmas and the New Year periods. In addition, access block may interrupt elective surgery which may have escalating effects on the whole system. Cancellation of elective surgery, for example, has been found to have an important effect on funding arrangements, hospital capacity and the way operating rooms are utilized [45].

\section{Medical, surgical wards and the ICU}

Pressure to admit patients more rapidly from the ED can result in patients being sent to 'outlier wards'; wards less likely to deliver specialized care. When bed occupancy rates are reduced, patient flow improves by allowing patient transfer to the wards, which, in turn, frees up EDs, so that patients from the waiting room or ambulance bay can be seen and processed, reducing ED length of stay, ambulance diversion and operating room cancellations [20,46-48].

\section{Potential solutions}

It has been reported that the efficiencies gained from successful implementation of national access targets, such as the 'four hour target', may lead to a one off improvement in capacity and access to beds through improvement in processes, possibly the equivalent of 5$8 \%$ capacity $[8,49]$. Access targets may help our health systems deal more effectively with the long-term growth in demand for acute beds of about $2-4 \%$ per year but cannot be the only solution. Increased physical bed capacity in hospitals in order to reduce bed occupancy levels is required.

Out of hospital, demand management strategies and improved community support are also necessary. In particular, the demand associated with aged care and mental health must be addressed as a matter of urgency so that sufficient resources are available for these patients to be treated in the community, thus avoiding acute hospital admission where appropriate.

Accurate audit or research data for the benefits/risks of introducing these targets are limited. Evaluation, continuous audit, and transparent dissemination of results are essential to allow flexible changes in response to outcomes at the local level, and across the system. Consideration of each hospital's differing circumstances, for example, local populations and disease severity, availability of specialized resources or staffing models, must guide local implementation. Rigorous and independent monitoring at the national level must be mandatory to safeguard quality clinical care, and to ensure optimal use of health system resources [49].

In summary, the patients most affected by access block and overcrowding are those who, because of their medical condition require unplanned admission to hospital $[6,7,10,13-15]$. The reasons for some patient groups being more affected by access block are multifactorial and complex. Deleterious effects as a result of overcrowding and access block have been found in trauma patients [39], and include: Increased delays in transfer to ICU [46-48]; delays in pain treatment [6,7]; increased numbers of patients who did not wait for treatment [36]; increase in patient adverse events [37]; and increased mortality [38,39].

Additional resources will be required for redesigning current processes, improving access to diagnostic and other support services and making effective use of hospital infrastructure over extended hours. In particular, appropriate, and improved, staffing of EDs, general wards and diagnostic and support services is necessary to ensure prompt, timely and safe care for patients, 24 hours per day, every day [49].

Resources must support the continued ability of the ED, hospital and community providers to fulfill clinical education, training and supervisory obligations in accordance with national professional guidelines and standards [49]. In relation to the evidence about what works and what does not work, the majority of the evidence on interventions comes from single hospital rather than multicenter studies. In order to improve the type and success of access block interventions more multilevel studies are needed instead of retrospective or observational/descriptive studies. 


\section{Conclusion}

If we considered access block as a disease then we would be forced to treat only some of the symptoms, but the fundamental condition would remain unaffected $[7,10]$. As indicated above, many interventions have been partially successful, but as long as the fundamental causes remain, the symptoms sooner or later will re-emerge [7].

In large EDs, $40 \%$ or more of staff time is spent caring for patients who are waiting for a bed, rather than looking after new emergency patients [50]. An emphasis on what is clinically appropriate for patients underpins success in improving access to care. In relation to potential solutions, in addition to adequate mental health and transitional care beds (flexible beds) there is a need for robust, long-term data collection and system dynamic analysis [42]. Finally, transparency and free access to data must be made available to those who understand the health care system and can provide possible ways to improve the system. This must include researchers and clinicians as well as policy makers and bureaucrats.

\section{Competing interests}

The authors declare that they have no competing interests.

\section{Author details}

'The Simpson Center for Health Systems Research, Liverpool Hospital, Locked Bag 7103, Liverpool BC, NSW, 1871, Australia. ${ }^{2}$ Department of Emergency Medicine, Australasian College for Emergency Medicine, 34 Jeffcott Street, West Melbourne, VIC 3003, Australia.

\section{Published: 22 March 2011}

\section{References}

1. Ellis J: The superstring: theory of everything, or of nothing? Nature 1986, 323:595-598.

2. Sklar DP, Handel DA, Hoeskstra I, Baren J, Zink B, Hedges J: The future of Emergency Medicine: an Evolutionary Perspective. Acad Med 2010, 85:490-495.

3. Scott I, Vaughan L, Bell D: Effectiveness of acute medical units in hospitals: a systematic review. Int J Qual Health Care 2009, 21:397-407.

4. Walters EH, Dawson DJ: Whole-of-hospital response to admission access block: the need for a clinical revolution. Med J Aust 2009, 191:561-563.

5. Australasian College for Emergency Medicine (2006) Standard Terminology. [http://www.acem.org.au/media/policies_and_guidelines/ P02_-_Standard_Terminology_16.04.09.pdf] Accessed November 2010.

6. Australasian College for Emergency Medicine (2004) Access Block and overcrowding in emergency departments. Online report. [http://www. acem.org.au/media/Access_Block1.pdf] Accessed November 2010.

7. Forero R, Hillman K, McCarthy S, Fatovich D, Joseph A, Richardson DW: Access block and ED overcrowding. Emerg Med Australas 2010, 22:119-135.

8. Orr J: The good, the bad, and the four hour target. BMJ 2008, 337:a195.

9. Commission for Healthcare Audit and Inspection (2009) Investigation into Mid Staffordshire NHS Foundation Trust. [http://www.cqc.org.uk/_db/_ documents/Investigation_into_Mid_Staffordshire_NHS_Foundation_Trust. pdf] Accessed November 2010

10. Braitberg G: Emergency department overcrowding: dying to get in? Med J Aust 2007, 187:624-625.

11. Fatovich DM, Hughes G, McCarthy SM: Access block: it's all about available beds. Med J Aust 2009, 190:362-363.

12. Bain CA, Taylor PG, Mcdonell G, Georgiou A: Myths of ideal hospital occupancy. Med J Aust 2010, 192:42-43.

13. Cooke M, Fisher J, Dale J, McLeod E, Szczepura A, Walley P, Wilson S: Reducing attendances and waits in emergency departments. A systematic review of innovations. Report to the national coordinating centre for NHS Service Delivery and Organisation R\&D (NCCSDO), 2005. SDO, London [http://wrap.warwick.
ac.uk/134/1/WRAP_Szczepura_29-final-report.pdf] Accessed November 2010.

14. Anderson J, Bernath V, Davies J, Greene L, Ludolf S: Literature Review on Integrated Bed and Patient Management. Centre for Clinical Effectiveness Monash Institute of Public Health and Planning and Development Unit Southern Health: Melbourne, Australia, 2001

15. Dwyer J, Jackson T: Literature Review: Integrated Bed and Patient Management. Commissioned by the Patient Management Task Force, Department of Human Services Victoria, Australia, 2001.

16. Mace SE, Graff L, Mikhail M, Ross M: A national survey of observation units in the United States. Am J Emerg Med 2003, 21:529-533.

17. Caplan GA, Williams AJ, Daly B, Abraham K: A randomized, controlled trial of comprehensive geriatric assessment and multidisciplinary intervention after discharge of elderly from the emergency department-the DEED II study. J Am Geriatr Soc 2004, 52:1417-1423.

18. Dunn R: Reduced access block causes shorter emergency department waiting times: An historical control observational study. Emerg Med (Aust) 2003, 15:232-238.

19. Donald KJ, Smith AN, Doherty S, Sundararajan V: Effect of an on-site emergency physician in a rural emergency department at night. Rural and Remote Health, 2005 [http://www.rrh.org.au/publishedarticles/article_ print_380.pdf] Accessed November 2010.

20. Levin SR, Dittus R, Aronsky D, et al:: Optimizing cardiology capacity to reduce emergency department boarding: a systems engineering approach. Am Heart J 2008, 156:1202-1209.

21. Han JH, Zhou C, France DJ, et al:: The effect of emergency department expansion on emergency department overcrowding. Acad Emerg Med 2007, 14:338-343.

22. Cameron PA, Campbell DA: Responses to access block in Australia: Royal Melbourne Hospital. Med J Aust 2003, 178:109-110.

23. Ruffin RE, Hooper JK: Responses to access block in Australia: Queen Elizabeth Hospital Medical Division. Med J Aust 2003, 178:104-105.

24. Ashby RH: Responses to access block in Australia: Queensland. Med J Aust 2003, 178:107-108

25. Combs S, Chapman R, Bushby A: Evaluation of fast track. Accid Emerg Nurs 2007, 15:40-47.

26. O'Brien D, Williams A, Blondell K, Jelinek GA: Impact of streaming "fast track" emergency department patients. Aust Health Rev 2006, 30:525-532.

27. Sprivulis $P$, Gerrard B: Internet-accessible emergency department workload information reduces ambulance diversion. Prehospital Emerg Care 2005, 9:285-291

28. Tambimuttu J, Hawley R, Marshall A: Nurse-initiated x-ray of isolated limb fractures in the emergency department: research outcomes and future directions. Aust Crit Care 2002, 15:119-122.

29. Cooper MA, Lindsay GM, Kinn S, Swann IJ: Evaluating emergency nurse practitioner services: a randomized controlled trial. J Adv Nurs 2002, 40:721-730

30. American College of Emergency Physicians (2008) ACEP psychiatric and substance abuse survey 2008. [http://www.acep.org/uploadedFiles/ACEP/ Advocacy/federal_issues/PsychiatricBoardingSummary.pdf] Accessed November 2010

31. Schull MJ, Szalai JP, Schwartz B, Redelmeier DA: Emergency department overcrowding following systematic hospital restructuring: trends at twenty hospitals over ten years. Acad Emerg Med 2001, 8:1037-1043.

32. Takakuwa KM, Shofer FS, Abbuhl SB: Strategies for dealing with emergency department overcrowding: a one-year study on how bedside registration affects patient throughput times. J Emerg Med 2007, 32:337-342.

33. Wilson $\mathrm{H}$ : Co-locating primary care facilities within emergency departments: brilliant innovation or unwelcome intervention into clinical care? NZMed J 2005, 118:U1633.

34. Van Uden CJT, Crebolder HFJM: Does setting up out of hours primary care cooperatives outside a hospital reduce demand for emergency care? Emerg Med J 2004, 21:722-723.

35. Bond K, Ospina MB, Blitz S, et al.: Frequency, determinants and impact of overcrowding in emergency departments in Canada: a national survey. Healthc Q 2007, 10:32-40.

36. Mohsin M, Forero R, leaci S, Bauman A, Young L, Santiano N: A population follow up study of patients who left an emergency department without being seen by a medical officer. Emerg Med J 2007, 24:175-179.

37. Foster AJ, Murff HJ, Peterson JF, Gandhi TK, Bates DW: The incidence and severity of adverse events affecting patients after discharge from the 
hospital. Ann Intern Med 2005, 138:161-167.

38. Fatovich DM: Effect of ambulance diversion on patient mortality: how access block can save your life. Med J Aust 2005, 183:672-673.

39. Richardson DB: Increase in patient mortality at 10 days associated with emergency department overcrowding. Med J Aust 2006, 184:213-216.

40. Sprivulis PC, Da Silva JA, Jacobs IG, Frazer AR, Jelinek GA: The association between hospital overcrowding and mortality among patients admitted via Western Australian emergency departments. Med J Aust 2006, 184:208-212.

41. The College of Emergency Medicine: (2008) The Way Ahead 2008-2012. Strategy and quidance for Emergency Medicine in the United Kingdom and the Republic of Ireland. [http://www.collemergencymed.ac.uk/CEM/ About\%20the\%20College/Current \%201ssues\%20and\%20Statements/ The\%20Way\%20Ahead/default.asp] Accessed November 2010

42. Australian Medical Association: Position statement on quality and safety in public hospitals. Kingston, ACT, 2006. [http://ama.com.au/node/2540] Accessed November 2010.

43. Imaging Performance Partnership: Elevating Interdepartmental Workflow: Best Practices for Optimizing Emergency and Patient Radiology Throughput. The Advisory Board Company, Washington; 2009.

44. Worster A, Fernandes CBM, Malcolmson C, Eva K, Simpson D: Identification of root causes for emergency diagnostic imaging delays at three Canadian hospitals. J Emerg Nursing 2006, 32:276-280.

45. Thomas J, Nicholas C: Effect of a holiday services reduction period on a holspital's emergency department access block. Emerg Med Australas 2007, 19:136-142.
46. Ou L, Young I, Chen J, Santiano N, Baramy LS, Hilman K: Discharge delay in acute care: reasons and determinants of delay in general ward patients. Aust Health Rev 2009, 33:513-521.

47. Frost SA, Alexandrou E, Bogdanovski T, Salamonson Y, Parr MJ, Hillman KM: Unplanned admission to intensive care after emergency hospitalisation: Risk factors and development of a nomogram for individualised risk. Resuscitation 2009, 80:224-230.

48. Carr BG, Kaye AJ, Wiebe DJ, Gracias VH, Schwab CW, Reilly PM: Emergency department length of stay: a major risk factor for pneumonia in intubated blunt trauma patients. J Trauma 2007, 63:9-12.

49. Australasian College for Emergency Medicine (2010) ACEM Statement on National Time Based Emergency Access Targets in Australia and New Zealand. [http://www. acem.org.au/media/media_releases/Statement_4hr_ target.pdf] Accessed November 2010.

50. Richardson D: Access block point prevalence survey. Carried out by the Road Trauma and Emergency Medicine Unit, Australian National University on behalf of the Australasian College for Emergency Medicine, 2009. [http://www.acem.org.au/media/Access_Block_ Update_2009-2_201109_.pdf] Accessed November 2010.

\section{doi:10.1186/cc9998}

Cite this article as: Forero R, et al: Access block and emergency department overcrowding. Critical Care 2011, 15:216. 